\title{
Research on Contagion Effects of Chinese Bonds
}

\author{
Liu Jiansheng \\ Central University of Finance and Economics \\ School of Economics \\ China
}

\begin{abstract}
In recent years, the global economy has faced considerable downward pressure. The default of a company often leads to the default or even bankruptcy of the related companies, forming a "domino effect". With the continuous improvement of financial market openness and correlation, the contagion effect of individual and industry caused by default dependence is also increasing, and the systemic financial risk caused by contagion will be more destructive. The 2008 global financial crisis proved difficult to warn of. However, before the financial crisis escalated, systemic financial risks went through a long process of risk accumulation. Therefore, under the background of increasingly close economic links between domestic industries and the international economy, it has become an important subject for academia and regulators to study the contagion mechanism of systemic financial risks and prevent the occurrence of systemic financial risks.

In this paper, theoretical analysis and empirical analysis are combined, and quantile regression method is used to study Covar. Four industries, namely coal, steel, real estate and bank, are creatively selected to study the contagion effect between individuals and industries. It is found that coal enterprises in Shanxi, iron and steel enterprises in east China, state-owned real estate enterprises and state-owned big Banks have lower risks due to their strong competitiveness in their respective fields, but the risk spillover effect on the industry is differentiated.
\end{abstract}

Keywords: contagion effect; Covar; quantile regression

\section{Literature review on infectious effects}

Defaults have become more common in recent years. Many scholars have discussed the causes and nature of default, and more and more attention has been paid to the study of default infection. In recent years, European and American researchers have also devoted themselves to the study of credit contagion, so far a large number of empirical studies have confirmed the existence of credit contagion.

In the study of credit transmission, it is generally believed that a small number of shocks initially affect only a few institutions and regional economies. As credit quality deteriorates, the resulting contagion will affect other industries. Credit contagion may occur not only in the financial sector, but also in the production sector, which is triggered by the loan relationship between buyers and sellers through trade loans. If firms are interconnected, customer defaults can lead to a series of failures, and this contagion is more common during recessions (Kiyotaki\& Moore, 1997). The borrowing and trading relationship between enterprises is a typical way to generate credit contagion (Allen\&gale,2000).

Based on the interaction between enterprises and their business partners, Giesecke\& Weber(2004) built a Benoulli mixture model to measure greater infectivity. They obtain an overall approximation of the distribution of portfolio losses and quantify the relationship between global economic volatility, the extent of corporate interaction and the transfer of asset losses. They found that cyclical fluctuations in the economic base dominated average losses, a systemic risk that could not be avoided by diversifying risk. The intensity of the loss fluctuations caused by the contagion effect depends on the complexity of the business relationship network, a risk that can be controlled by managing relationships between firms or debt.

Allen\& Gale(2000) studied the different responses of different inter-bank network structures to contagion on the basis of consumer liquidity preference defined by Diamond \& Dybvig (1983). They point out that when each node in a network links to all other nodes, a "complete network" is formed between them. It also proves that the complete network structure is better able to withstand serious infections, because the losses will be Shared by more Banks, thus avoiding the chain system harm caused by excessive concentration of risks. On the other hand, in an "incomplete network", the failure of one bank could upend the entire banking system. 
In the follow-up study on such issues, Freixas et al. (2000) introduced epidemiological research methods into financial network analysis through the analysis of liquidity shock, and Gai\& Kapadia (2007) confirmed the comparative advantages of "complete network structure" in anti-infection to some extent.

Jarrow\&Yu (2001) was the first to consider the credit contagion of related enterprises under the intensity model. Under their framework, a model has been established for the intensity of default of surviving enterprises. However, this model only applies to one-way infection and does not include cross contamination. Here, companies fall into two categories: tier 1 and tier 2 . The default intensity of first-level enterprises only depends on the large economic environment, while the default intensity of second-level companies not only depends on macroeconomic factors, but also depends on the credit rating of major companies. Yu then ran a randomized simulation in 2002. He obtained the default correlation between the contracted model and his own model under different parameters, and further developed the original Jarrow $\& Y u$ model, which used the death theory to reconstruct the model in the survival function.

Frey\& Backhaus (2004) confirmed that the intensity of defaults depends on the average level of the overall economy. At the same time, they expanded Jarrow \& Yu's idea. Firstly, the default process is established as a conditional finite markov chain. The state of the chain includes the default state of all creditors at a certain point in time and the transition probability related to the default intensity. Second, they model default correlations in portfolios. Generally speaking, in a large portfolio, the model should be able to grasp the main characteristics of relevant enterprises, and at the same time, the model is relatively simple and easy to calculate and simulate. To achieve this goal, they divided the portfolio of companies into similar groups and built a model in which the intensity of default of a given company mainly depends on the distribution of defaulters within the same group. Such interactions, called mean field interactions in interacting particle systems, are very useful for studying combinatorial loss distributions.

Duffie et al. (2007) considered introducing two variables into the reduction model to predict the probability of conditional default: one is the unique variable reflecting a single company, that is, heterogeneous factors, such as the company's stock return, or the proportion of defaulting companies in the total number of companies; The other variable reflects the macro economy. It can choose interest rates or stock returns that reflect how well the company is doing. In this model, in addition to assuming that the default process and exit process of the company need to meet double randomness, certain independence conditions are also required. In addition, the model does not take into account the possible risk of infection, which could lead to an underestimate of the risk if there are infectious effects. Xieshangyu and Zhou yong (2009) introduced a default infection model to study the transmission of financial risks between industries. The parameters in the model can study the contagion effect of default quantitatively and explain how to control the transmission of risk by adjusting the parameters. However, policy analysis suggests that this depends on the risk of infection and immune processes, which need to meet the nature of the Markov process and require a linear proportion of its intensity. Xieshangyu, Wang shouyang and Zhou yong (2011) considered the influence of dynamic information of multi-stage state variables on default risk under the framework of simplified model, and constructed the default prediction model by taking macro and individual factors into consideration. However, they did not give any empirical analysis and could not test their proposed model in the actual situation.

\section{The Empirical Study of Contagion Effect}

In order to measure the systemic risk of a single enterprise to the industry, this paper intends to study the coal, steel, real estate and banking industries, mainly based on the fact that the four industries are pillar industries of China's economy, which have great influence on the macro economy and strong practical significance. In addition, the four industries are upstream and downstream relations, which theoretically have mutual contagion effect. Therefore, this paper will study the contagion effect of a single enterprise on the industry.

\subsection{Calculation and estimation method of Covar}

This article chose the Covar method based on quantile regression model, because the Covarcan accurately depict the research object in the tail risk under extreme events, and on the quantile regression to economic activity in most has the characteristic of "rush thick tail" or heteroscedasticity data is described, on the other hand through the set be explained variable quantile, the explanation variable regression can be showed certain extreme position data. Then, the Covar method based on quantile regression model can measure the individual's own risk in extreme situations and describe the spillover effect on other individuals and the whole system, so that the systematic risk of itself and its influence in the whole system can be accurately measured.

\subsection{Data and processing}

Ten representative listed companies of coal, steel, real estate and banking industry from January 2010 to April 2019 were selected as samples to calculate the influence of individuals on the industry based on weekly closing price data. 
Formula $\mathrm{R}=\mathrm{Pt}$ / pt-1 was used to calculate the weekly return rate, where Pt represents the weekly closing price of the stock of the listed institution. The rate of return of the industry is calculated by Shenwan industry index, which is still calculated by formula $\mathrm{R}=\mathrm{Pt} / \mathrm{pt}-1$.

\subsection{State variable selection}

The state variables used to calculate the time series of individual institutions' contribution to industry risks and their calculation methods are shown in table 1 . Weekly data were used for state variables, and the sample interval was from January 2010 to April 2019. Data from the Wind database.

Table 1State variable selection

\begin{tabular}{|c|l|l|}
\hline $\begin{array}{c}\text { State } \\
\text { variable }\end{array}$ & \multicolumn{1}{|c|}{ Calculation method } & \multicolumn{1}{c|}{ Variable description } \\
\hline M1 & $\begin{array}{l}\text { Interbank pledged repo rate (3 } \\
\text { months) - Treasury yield (3 months) }\end{array}$ & Measure the tightness of market funds \\
\hline M2 & $\begin{array}{l}\text { Treasury yield to maturity 10 years - } \\
\text { Treasury yield 1 year }\end{array}$ & $\begin{array}{l}\text { Measure the difference between investors' } \\
\text { expectation of long-term and short-term } \\
\text { government investment }\end{array}$ \\
\hline M3 & $\begin{array}{l}\text { Yield to maturity (AA) 1 year - } \\
\text { Treasury bond yield (1 year) }\end{array}$ & Measure credit spreads \\
\hline
\end{tabular}

Calculating the time series of Covar, it is necessary to conduct normality test and stationarity test for the data. Through the test, it was found that the $\mathrm{p}$ values corresponding to jarque-bera statistics of all yield sequences were less than 0.05 , so the null hypothesis was rejected, that is, the yield sequences were not normally distributed. From the kurtosis of return rate series, the kurtosis of all return rate series is greater than that of normal distribution. According to the q-q diagram of the yield rate series, each yield rate series shows the characteristics of downward bending at the top and upward rising at the bottom. These two characteristics indicate that the yield rate series shows a typical characteristic of "sharp peak and thick tail". Therefore, the quantile regression method is more accurate in the estimation. In order to prevent pseudo-regression, it is necessary to perform stationarity test on the yield sequence before quantile regression. According to the results of ADF test, the $\mathrm{p}$ values corresponding to the ADF test $\mathrm{t}$ statistics of all yield series are close to 0 , so the null hypothesis of unit root is rejected, and all yield series are stationary. All the quantile regression in this paper adopted $5 \%$ quantile level.

\subsection{Under the static background, the risk spillover effect of a single institution on the industry}

\subsubsection{Analysis of the influence of coal institution on the industry}

The coal industry is divided into coal enterprises by region in this paper. Representative local enterprises are selected, covering Shandong, Shanxi, Hebei, Anhui, etc. According to the average size of Var, they are Shandong, Anhui, Hebei, Shanxi and State-owned enterprises respectively. The main reasons are as follows.

Table 2Coal industry test results

\begin{tabular}{|c|c|c|c|c|c|}
\hline \multirow{13}{*}{$\begin{array}{l}\text { Coal } \\
\text { industry }\end{array}$} & Classification & Company & Var & Covar & $\triangle$ Covar \\
\hline & \multirow{3}{*}{$\begin{array}{l}\text { State-owned } \\
\text { enterprises }\end{array}$} & $\begin{array}{l}\text { China } \\
\text { Shenhua }\end{array}$ & 5.99 & 7.61 & 7.68 \\
\hline & & $\begin{array}{l}\text { China coal } \\
\text { energy }\end{array}$ & 6.25 & 7.30 & 7.30 \\
\hline & & Mean & 6.12 & 7.45 & 7.49 \\
\hline & Shandong & Yanzhou & 10.43 & 8.55 & 8.55 \\
\hline & \multirow{4}{*}{ Shanxi } & Datong & 8.58 & 7.81 & 3.88 \\
\hline & & Yangquan & 9.62 & 7.51 & 3.65 \\
\hline & & Xishan & 8.65 & 8.11 & 4.94 \\
\hline & & Mean & 8.95 & 7.81 & 4.15 \\
\hline & \multirow{3}{*}{ Hebei } & $\begin{array}{l}\text { Jizhong } \\
\text { energy }\end{array}$ & 9.67 & 8.38 & 4.63 \\
\hline & & Kailuan & 8.25 & 8.41 & 4.57 \\
\hline & & Mean & 8.96 & 8.39 & 4.6 \\
\hline & Anhui & $\begin{array}{l}\text { Huaibei } \\
\text { Mining }\end{array}$ & 9.52 & 9.27 & 4.34 \\
\hline
\end{tabular}


State-owned enterprises: State-owned enterprises have a strong shareholder background and have obvious advantages in coal resources reserves, production and coal quality and coal type, etc. In particular, large state-owned enterprises have the advantage of coal and electricity integration, so they can resist strong periodicity and have the minimum risk of a single enterprise.

Shanxi and Hebei coal enterprises: Shanxi is rich in coal resource endowment, large in scale, moderate in mining cost and good in transportation, so the risk of a single enterprise is relatively small. Hebei is also a major coal producer in China, with relatively low mining and transportation costs. Large coal enterprises mainly include Jizhong Energy and Kailuan Shares.

Shandong and Anhui: the major risk of a single coal enterprise in the two provinces is mainly due to the relative concentration of local coal resources. Only Yankuang group and Shandong Energy group are the largest coal enterprises in Shandong, while only Huainan Mining and Huaibei Mining are the largest coal enterprises in Anhui. However, Shandong and Anhui also have regional advantages, but the geological conditions are more complex and the mining costs are higher, so the risks are relatively large.

According to the size of Covar, Anhui, Shandong, Hebei, Shanxi and State-owned enterprises were ranked respectively. We found that except for the adjustment of the order of Shandong and Anhui, when considering the risks of individual coal enterprises in other regions, the ranking of risks of coal industry is basically the same as that of individual coal enterprises. This indicates that a single coal enterprise has a small risk, and the risk spillover effect on the industry is generally small. Both Shanxi and central enterprises have stronger scale and channel advantages, so the risk spillover effect is also the smallest.

\subsubsection{Analysis of the impact of steel institution on the industry}

According to the empirical test, the order of Var mean is respectively northwest, northeast, north China and east China. The order of the mean value of Covar is northwest, northeast, north China and east China respectively, which are in the same order as the value of Var.

In terms of regional competitiveness, iron ore purchasing cost and transportation cost are the important factors affecting the cost. East China is dominated by imported ore, and the price of imported ore is generally lower than that of domestic ore. Due to its proximity to ports and low transportation costs, the comprehensive cost of iron ore in east China is low and the competitiveness of iron ore is the strongest. The risks of enterprises in the region and the risk spillover effect on the industry are the least.

Table 3 Steel industry test results

\begin{tabular}{|c|c|c|c|c|c|c|}
\hline \multirow{15}{*}{$\begin{array}{l}\text { Steel } \\
\text { industry }\end{array}$} & & Classification & Company & Var & Covar & $\Delta$ Covar \\
\hline & \multirow{4}{*}{$\begin{array}{l}\text { The North } \\
\text { of China }\end{array}$} & Hebei & Hegang & 6.88 & 7.06 & 2.75 \\
\hline & & Beijing & Shougang & 7.14 & 7.40 & 2.49 \\
\hline & & Shanxi & Taigang & 7.64 & 7.80 & 4.03 \\
\hline & & & Mean & 7.22 & 7.42 & 3.09 \\
\hline & \multirow{4}{*}{$\begin{array}{l}\text { The East } \\
\text { of China }\end{array}$} & Shanghai & Baogang & 5.78 & 7.82 & 3.54 \\
\hline & & Jiangsu & Shagang & 8.18 & 6.88 & 0.90 \\
\hline & & Shandong & Shangang & 7.22 & 7.54 & 1.96 \\
\hline & & & Mean & 7.06 & 7.41 & 2.13 \\
\hline & \multirow{3}{*}{$\begin{array}{l}\text { The north } \\
\text { east }\end{array}$} & \multirow{3}{*}{ Liaoning } & Angang & 7.27 & 7.54 & 4.01 \\
\hline & & & Bengang & 7.73 & 7.68 & 3.03 \\
\hline & & & Mean & 7.5 & 7.61 & 3.52 \\
\hline & \multirow{3}{*}{$\begin{array}{l}\text { The } \\
\text { northwest }\end{array}$} & Neimenggu & Baogang & 8.31 & 6.99 & 2.51 \\
\hline & & Xinjiang & Bayi & 10.59 & 8.34 & 3.45 \\
\hline & & & Mean & 9.45 & 7.66 & 2.98 \\
\hline
\end{tabular}

North China area and higher levels of domestic ore reserves, but more for a total of associated minerals and super lean ore, mining cost slightly higher, but the most main large steel mills in China are concentrated in east China and north China region, so with the scale of the enterprise, and the local demand is relatively strong, steel mills in north China still has strong competitiveness, therefore, enterprises in north China's own risk spillover effects and the risk of the industry is relatively small. Domestic in the mine are parts of the cost is low, among them, the Liaoning province will output the minimum cost of iron ore concentrate, makes the northeast area have a cost advantage, but because of the northeast region's economic downward pressure is bigger, the steel freight lead to comprehensive cost is higher, so the enterprise in the northeast of risk and the spillover effect was third. 
Due to the poor market environment in northwest China, railway and road transportation are needed for imported mines after they arrive at the port, which leads to high transportation costs. Therefore, Var and Covar have the highest values. To sum up, east China and north China have relatively low comprehensive cost and relatively small enterprise risk, while northeast and northwest China have relatively high comprehensive cost and relatively large enterprise risk due to poor market.

\subsubsection{Analysis of the influence of real estate institution on the industry}

The real estate industry plays an important role in China's economy. In the bond market, there have been default enterprises such as Huaye Shares, Zhonghong Shares, Yinyi Shares and Zhengyuan real estate. The real estate industry is a capital-intensive industry, and the refinancing ability of enterprises plays an important role in the risk of debt repayment. Due to different shareholders' backgrounds, the financing cost of real estate enterprises in the market plays a crucial role, so this paper divides real estate enterprises into state-owned enterprises and private enterprises. Through research, it is found that the Var value of private enterprises is higher, and the Covar value is also higher, indicating that the individual risk in the real estate industry and the risk spillover effect of individuals on the industry change in the same direction, and both are private enterprises that generate greater losses. The reason is that private real estate enterprises are more aggressive and tend to expand in a pro-cyclical environment. When faced with the policy of tightening liquidity by financial institutions, private real estate enterprises are more likely to be pulled out of loans, so the individual risk and the risk spillover effect on the industry are both greater.

Table 4Real Estate industry test results

\begin{tabular}{|c|c|c|c|c|c|}
\hline \multirow{13}{*}{$\begin{array}{l}\text { Real } \\
\text { estate }\end{array}$} & Classification & Company & Var & Covar & $\Delta$ Covar \\
\hline & \multirow{7}{*}{$\begin{array}{l}\text { State-owned- } \\
\text { enterprise }\end{array}$} & Vanke & 6.95 & 8.05 & 3.17 \\
\hline & & Poly Group & 8.88 & 7.90 & 9.73 \\
\hline & & Greenland & 8.89 & 7.57 & 2.17 \\
\hline & & Huaxia & 8.29 & 7.95 & 2.62 \\
\hline & & Huarun & 7.28 & 9.21 & 3.46 \\
\hline & & COHL & 6.96 & 8.84 & 2.85 \\
\hline & & Mean & 7.87 & 8.25 & 4 \\
\hline & \multirow{5}{*}{$\begin{array}{l}\text { Private } \\
\text { interprise }\end{array}$} & Hengda & 10.01 & 8.68 & 2.79 \\
\hline & & Longhu & 7.26 & 8.82 & 3.22 \\
\hline & & Biguiyuan & 8.25 & 9.62 & 3.31 \\
\hline & & Fuli & 8.12 & 8.47 & 2.61 \\
\hline & & Mean & 8.41 & 8.90 & 2.98 \\
\hline
\end{tabular}

\subsubsection{Analysis of the impact of bank institution on the industry}

This paper divides the banking industry into two categories: State-owned Banks and stock-holding Banks. Through the empirical test, it is found that the average risk of state-owned Banks is smaller, and the risk spillover effect on the whole banking industry is greater. This is mainly because state-owned big bank, with its strong shareholder background and nationwide network advantages, can obtain better customer resources, better internal mechanism and higher risk control level, so its own risks are relatively small. At the same time, the risk spillover effect on the banking industry is greater because of the larger scale and more important status of the State-owned Banks in the whole banking industry.

Table 5Bank industry test results

\begin{tabular}{|c|c|c|c|c|c|}
\hline \multirow{13}{*}{$\begin{array}{l}\text { Bankind } \\
\text { ustry }\end{array}$} & Classification & Company & Var & Covar & $\Delta$ Covar \\
\hline & \multirow{5}{*}{$\begin{array}{l}\text { State-owned } \\
\text { bank }\end{array}$} & ICBC & 4.58 & 6.08 & 3.09 \\
\hline & & $\mathrm{BOC}$ & 4.20 & 5.79 & 2.81 \\
\hline & & $\mathrm{CCB}$ & 5.66 & 6.76 & 3.77 \\
\hline & & $\mathrm{BOC}$ & 5.05 & 5.28 & 2.76 \\
\hline & & Mean & 4.87 & 5.98 & 3.11 \\
\hline & \multirow{7}{*}{$\begin{array}{l}\text { Stock-holding } \\
\text { Bank }\end{array}$} & CMB & 5.31 & 6.24 & 3.43 \\
\hline & & $\overline{\mathrm{CMBC}}$ & 5.30 & 5.63 & 3.21 \\
\hline & & Citic Bank & 6.59 & 5.92 & 2.64 \\
\hline & & Pingan & 6.92 & 5.93 & 3.34 \\
\hline & & SPDB & 5.18 & 5.67 & 3.02 \\
\hline & & $\overline{C I B}$ & 5.70 & 5.67 & 3.34 \\
\hline & & Mean & 5.83 & 5.84 & 3.16 \\
\hline
\end{tabular}




\section{3 under the dynamic background, the risk spillover effect of a single institution on the industry}

\subsubsection{Individual risk spillover effect in the coal industry}

Through empirical test, this paper estimates the time series of the marginal risk contribution of a single institution to the whole industry risk in extreme cases. China Shenhua, Jizhong Energy and Datong coal industry were selected for research.

\section{Figure1: Changes in $\Delta$ Covar of coal enterprises}

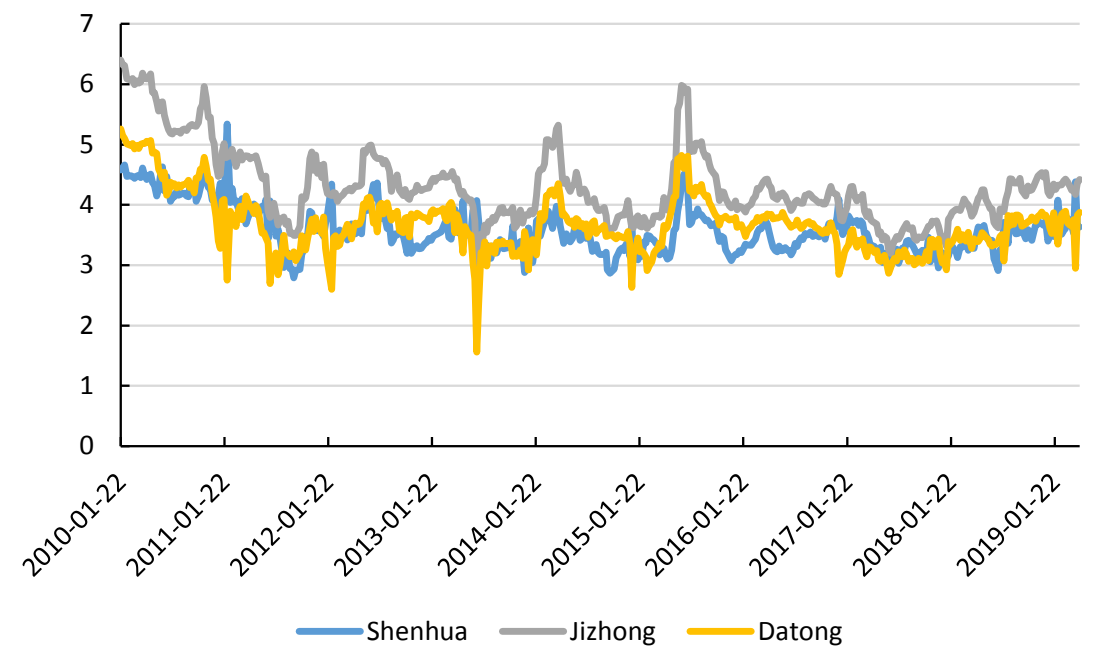

The figure above shows the dynamic changes of the time series of $\Delta$ Covar of three representative coal enterprises. Through individual comparison, the delta Covar of China Shenhua is relatively stable, indicating that China Shenhua itself has the most stable operation, and therefore the risk spillover effect on the industry is the minimum; Hebei energy has the highest average delta Covar, mainly because although Jizhong Energy is a large coal enterprise, the diversified operating background, the operating efficiency is relatively general, which leads to the largest risk spillover effect on the coal industry; Average risk of Datong coal overflow level is moderate, but compared with China's Shenhua, the industry under the condition of extreme risk volatility spillover effect, and shows that Datong coal by virtue of the advantage resources endowment, overall risk going lower energy, but met a trough in the coal industry, anti-risk ability is still is the Shenhua coal and electricity integration were lower, so the volatility spillover effects to the risk of the coal industry.

From the perspective of the curve trend, in 2018, China's economy was affected by the subprime mortgage crisis in the United States, and should have faced greater downward pressure. However, against the background of a series of loose policies, China's economy maintained an overall upward phase in 2011. As the upstream industry of the industrial chain, the coal industry is the leading indicator of macroeconomic changes. Therefore, in 2010, the systemic risk of China's coal industry began to turn downward from the peak, and the risk spillover effect $\Delta$ Covar under extreme conditions was also correspondingly compressed. Before 2016, the coal industry as a whole was in the stage of overcapacity, and the industry was under great downward pressure, and the enterprises in the whole industry were struggling to survive. Therefore, 2015 was a cut-off point, and the marginal overflow risk of individuals to the industry was greater when the industry prosperity was poor. Since then, China has implemented the policy of reducing coal capacity, and the prosperity of the industry has been greatly improved. Therefore, the systemic risk has been reduced, and the fluctuation degree of the curve has become smaller.

\subsubsection{Individual risk spillover effect in the steel industry}

The figure above shows the dynamic change of time series of delta Covar of three major steel enterprises. In terms of individual comparison, Baogang is the steel enterprise with the largest crude steel output in China. Due to its advanced equipment, wide radiation range, the strongest comprehensive strength and the strongest ability to absorb risks, the fluctuation of risk spillover effect on the industry is the least. Angang steel is also one of the top five steel enterprises in China's crude steel output, and the average risk spillover effect is small. Because the company is located in northeast China, although it has the inside information of the old industrial base, the transportation and marketing cost is high, so the operation is not as stable as Baogang in different cycle stages of the industry, and the spillover effect on the industry fluctuates. The stainless scale of Taigang is relatively small, mainly engaged in stainless steel business, the business scope is relatively narrow, compared with the ordinary steel market, the demand changes more, so the individual risk spillover effect on the industry fluctuation is the most violent. 
Figure2: Changes in $\Delta$ Covar of steel enterprises

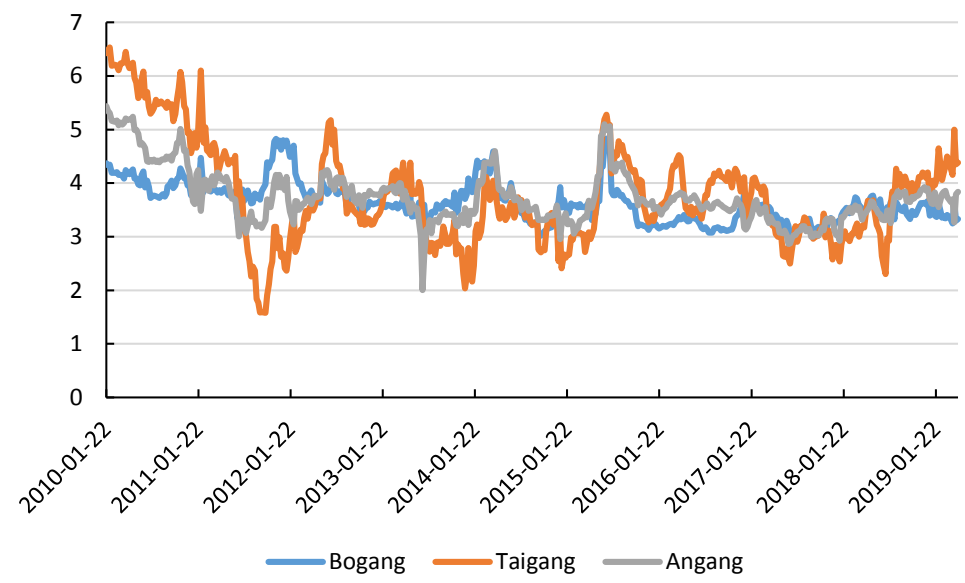

In terms of trend, as the downstream industry of the coal industry, the trend of delta Covar of steel enterprises is similar to that of the coal industry. Before 2016, the steel industry experienced a period of large fluctuations, mainly due to the downtrend of the prosperity of the industry, which compressed the risk spillover effect of the industry under extreme conditions. Since 2016, China began to implement steel capacity reduction policy, steel industry prosperity has been improved, the industry's overall ability to resist risks has been enhanced, therefore, the trend of delta Covar is relatively stable.

\subsubsection{Individual risk spillover effect in the real estate industry}

The figure shows the dynamic change of time series of delta Covar of three real estate enterprises. From the perspective of individual's contribution to the marginal risk of the industry, Hengda and China Overseas Holdings Limited have significantly greater risk spillover effect on the real estate industry, mainly due to the scale of the two enterprises leading the industry, so the contagion effect on the industry is also larger than that of the smaller Taihe Group.

\section{Figure3: Changes in $\Delta$ Covar of real estate enterprises}

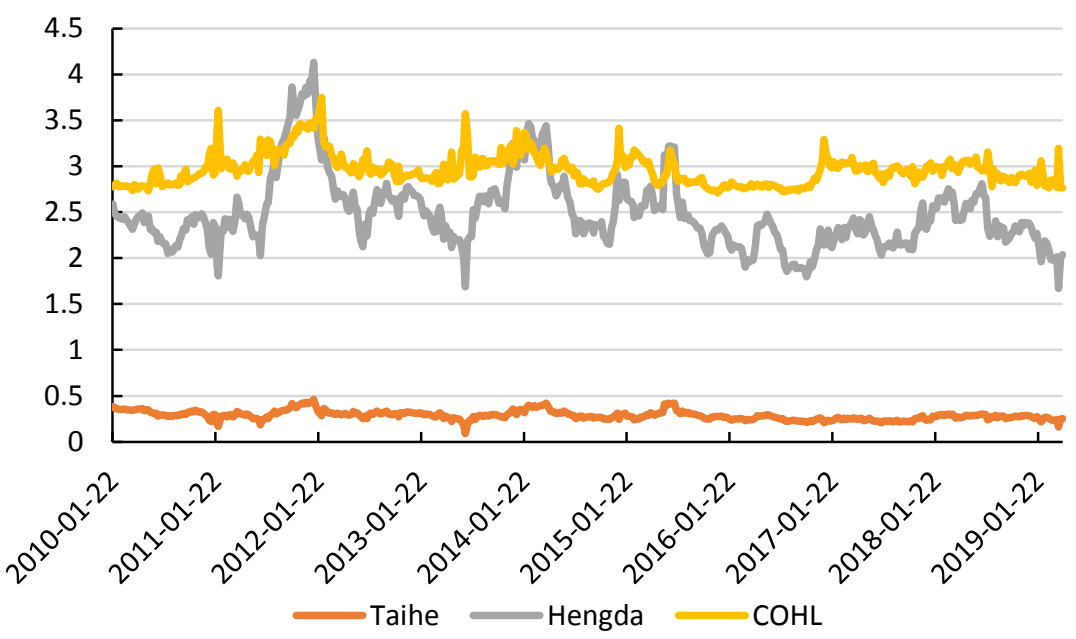

From the perspective of the changing trend, the real estate industry is affected by the policy of the industry, industry policy tightness alternate, in the face of enterprise real estate policy austerity, anti-risk ability performance different, therefore each enterprise's $\Delta$ Covar trend is different. As China Overseas Holdings Limited belong to the central government, shareholders have a better background than Hengda, and their own operations are more stable, the risk spillover effect on the real estate industry is more stable, Hengda style is more radical, and the solvency is not stable in the face of policy changes, so the marginal contribution to the industry fluctuates greatly.

\subsubsection{Individual risk spillovers in the banking industry}

As can be seen from the above figure, the industry risk of China's banking institutions and coal and steel industries have a high degree of fitting, but also experienced the change from high risk to low risk and from large volatility to small. 
In 2008, the subprime crisis was transmitted to China, and China hedged the risk of weaker market demand by expanding infrastructure and other means. Therefore, risks in the financial industry were always at a high level before 2016. With the gradual stabilization of the economy, the overall financial risk in China is decreasing and the volatility level is also decreasing. From the perspective of scale, China merchants bank and Industrial bank are both joint-stock Banks, which have greater fluctuations in the risk spillover effect on the industry. CCB is a state-owned big bank, which has stronger shareholder background and scale advantages, and more robust risk control ability, so the output of risk spillover effect on the banking industry is more stable.

\section{Figure4: Changes in $\Delta$ Covar of bank enterprises}

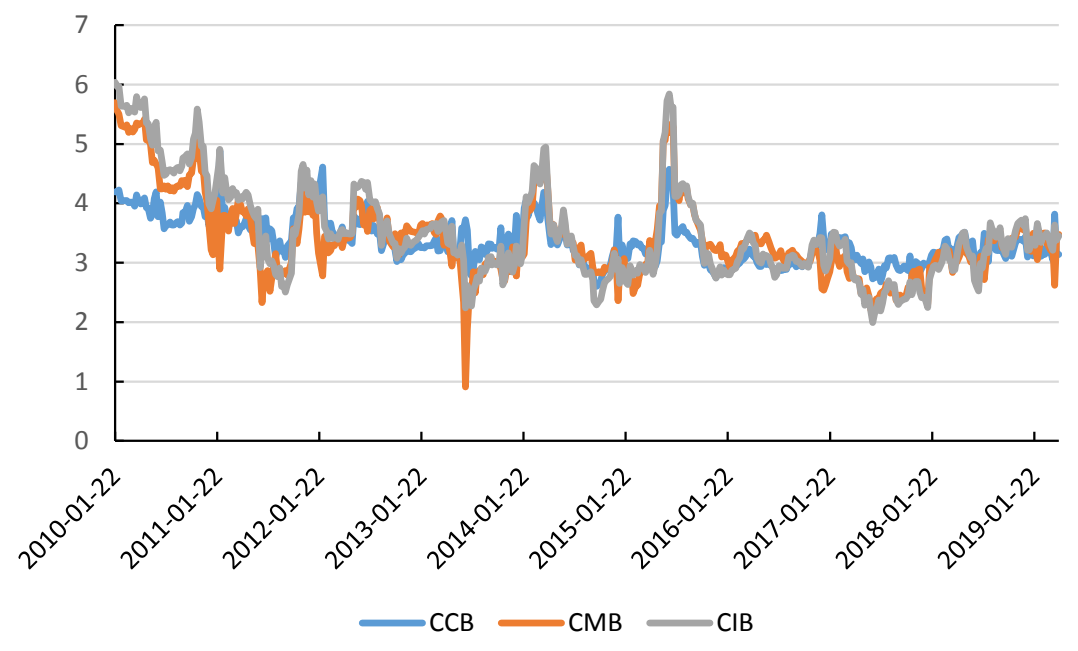

\section{Main conclusions}

After selecting several representative enterprises in coal, steel, real estate and banking industry, this paper finds that coal enterprises in the class of central government enterprises can resist strong periodicity by virtue of their strong shareholder background and the advantages of coal and electricity integration, and the risks of individual enterprises and the risk contagion effect on the industry are the least. Shanxi and Hebei are rich in coal resource endowment and large in scale, and the risks of individual enterprises and the risk spillover effect on the industry are relatively small. Although the coal enterprises in Shandong and Anhui provinces have a reasonable regional location, due to the complex geological conditions and high mining costs, their own risks and external contagion effects are the largest.

In the steel industry, the steel enterprises in east China have the strongest competitiveness due to the advantages of iron ore mining cost and freight, and their own risks and risk spillover effect on the industry are the least. Iron and steel enterprises in north China and northeast China are followed by large local demand or mining cost. Due to the poor market environment and high transportation cost, the steel enterprises in northwest China have the largest risk level and spillover effect on the industry.

Real estate real estate industry belongs to the capital-intensive industry, this paper points a state-owned enterprises and private companies and found that the corporation's own risk and risk spillover effects of the industry are larger, mainly private real estate enterprise management more radical, real estate and capital intensive industry, contraction of liquidity in financial institutions, private enterprise, more easy to take out loans, so the risk is greater.

Banking is related to the pillar industry of national economy and people's livelihood finance in our country, this article will banking divided into two categories, state-owned large and joint-stock Banks, found that the state-owned big row with the shareholders background and network advantages all over the country, and get a high quality of customer resources, more perfect risk control mechanism, therefore less risk of itself, but in the whole because of the large stateowned Banks in the size of bigger, more important position, so the spillover effects of banking risk is bigger.

\section{References}

Laeven L, Ratnovski L, long 11. Bank Size, Capital, and Systemic Risk:Some International Evidence[J]. Journal of Banking and finance, 2016,69:S25-34.

Marta G.,S.Simon.Causes and hazards of the euro area sovereign debt crisis:Pure andfundamentals basedcontagion[J].EconomicModelling,2016, 133-147. 
SedunovJ. What is the Systemic Risk Exposure of Financial Institutions?[J].Journal of Financial Stability, 2016 (24): $71-87$.

Chiu W C, Pena J I, Wang C W. Industry characteristics and financial risk contagion[J]. Journal of Banking \& Finance, 2015, 50:411-427.

AcemogluD, Ozdaglar A, Tahbaz-Salehi A., 2015, Systemic risk and stability in financial networks, The American Economic Review,Vo1.105 No.2,pp.564-608.

Duffie, AEckner, andSaita.Frailty Correlated Default.The Journal of Finance[J], 2009，2089-2123

Adrian,T., M.Brunnermeier.CoVaR[R] . Federal Reserve Bank of New York Staff Report No. 348, 2008

Zhou Y, XieS, YuanY. Statistical inference of default probability in credit risk models[J]. System Engineering: Theory\&Practice, 2008, 28(8) : 206-214.

Schoebucher, P.Information- DrivenDefault Contagion. working paper.2003.

Giesecke, K., Weber, S.CyclicalCorrelations, CreditContagion, and Portfolio Losses[J]. Journal of Banking and Finance, 2003.

Jarrow, R., Yu, F.CounterpartyRiskand the Pricing of DefaultableSecurities[J]. The Journalof Finance LVI, 2001 , 1765-1799.

RudigerDornbusch, YungChulPark, StijnClaessens.Contagion.How it spreads andHow it can be stopped[J]. Forthcoming World Bank Research Observer, 2000.

Allen, F.andD.Gale, FinancialContagion[J], Journal of Political Economy, 2000, 108, 1-33. 